\title{
RINOSPORIDIOSE: UMA DOENÇA RARA OU MAL DIAGNOSTICADA?
}

Bruno Sérgio Cruz da Silva, Carolina Ferreira Alves, Marina Brito dos Santos, Victorya do Nascimento Cavalcante, Francisco Xavier Palheta Neto. Rinosporidiose: uma doença rara ou mal diagnosticada? Revista Saúde

Dinâmica, vol. 4, núm. 2, 2021. Faculdade Dinâmica do Vale do Piranga.

\section{SAÚDE DINÂMICA - Revista Científica Eletrônica FACULDADE DINÂMICA DO VALE DO PIRANGA}

8ạ Edição 2021 | Ano III - no 2 | ISSN - 2675-133X 


\title{
Rinosporidiose: uma doença rara ou mal diagnosticada?
}

\author{
Rhinosporidiosis: a rare disease or a badly diagnosed one?
}

\author{
Bruno Sérgio Cruz da Silva ${ }^{1}$, Carolina Ferreira Alves ${ }^{1}$, Marina Brito dos Santos ${ }^{2}$, Victorya do \\ Nascimento Cavalcante ${ }^{3}$, Francisco Xavier Palheta Neto ${ }^{4}$ \\ 1. Aluno do segundo ano do curso de Medicina do Centro Universitário do Estado do Pará - CESUPA. \\ 2. Aluna do segundo ano do curso de Medicina do Centro Universitário do Estado do Pará- CESUPA. Membro da Liga \\ Acadêmica do Trauma - CESUPA. \\ 3. Aluna do segundo ano do curso de Medicina do Centro Universitário do Estado do Pará - CESUPA. Membro da Liga \\ Acadêmica de Anatomia - CESUPA. Estágio em Medicina Legal no Centro de Perícias Científicas Renato Chaves - \\ CPCRC. \\ 4. Médico Otorrinolaringologista, com Mestrado em Otorrinolaringologia pela Universidade Federal do Rio de Janeiro, \\ Doutorado em Neurociência e Biologia Celular pela Universidade Federal do Pará, Curso de Aperfeiçoamento em \\ Infectologia em Otorrinolaringologia na Fundação Oswaldo Cruz - FIOCRUZ. \\ Autor correspondente: Imecsufv@gmail.com
}

\section{Resumo}

A Rinosporidiose é uma doença de evolução lenta e processo inflamatório crônico, caracterizando-se pelo aparecimento de lesões polipoides nas mucosas, principalmente nasais e oculares. É causada pelo agente etiológico Rhinosporidium seeberi, um microrganismo hidrofílico que infecta peixes, anfíbios e mamíferos, como os seres humanos. Sendo hidrofílico seu acometimento em humanos é significativamente maior nos que entram em contato com água estagnada. Clinicamente, a sintomatologia depende diretamente do local acometido, podendo apresentar rinorreia e epistaxe nos acometimentos nasais e hemolacria e epífora em acometimentos oculares. Por mais que os papilomas pedunculados apresentados sejam atípicos, o diagnóstico diferencial ainda é importante visto todos os possíveis locais de acometimento, neste caso, o diagnóstico definitivo só pode ser alcançado por um exame histopatológico, vista a cultura do patógeno ser inviável. A doença pode ser recidiva mesmo quando se opta pela remoção cirúrgica, o tratamento de escolha, isso, provavelmente, decorre da disseminação dos endósporos para o tecido adjacente.

Palavras-chave: Rinosporidiose; Pólipos Nasais; Infecções por Mesomycetozoea; Hiperplasia.

\section{Abstract}

Rhinosporidiosis is a disease of slow progression and chronic inflammatory process, characterised by the presence of polypoid lesions in the mucosa, notably in the nasal and ocular. The damage is caused by the etiological agent Rhinosporidium seeberi, a hydrophilic microorganism that infects fish, amphibians, and mammals, such as humans. Being hydrophilic, their occurrence in humans is significantly greater in those that enter in contact with stagnated water. Clinically, the symptomatology depends directly on the affected area, possibly presenting rhinorrhea and epistaxis when affecting the nasal mucosa and hemolacria and epiphora on the ocular mucosa occurrences. Even though the presented pedunculated papillomas are atypical, the differential diagnosis is important given all the possible areas of occurrence, in this case the definitive diagnosis can only be reached through a histopathological examination, as the culture of the pathogen is unfeasible. The disease could be recurring even when opting for surgical removal, the preferred treatment. This probably occurs by the dissemination of the endospores to the adjacent tissue.

Key words: Rhinosporidiosis; Nasal Polyps; Mesomycetozoea Infections; Hyperplasia. 


\section{INTRODUÇÃO}

Atendendo ao nome de "Doença de Guillermo Seeber", "Blastomicose Rinosporidiótica", "Psorospermose Nasal” e "Granuloma Rinosporidiótico"; a Rinosporidiose, como é mais conhecida, trata-se de uma doença de evolução lenta e processo inflamatório crônico. É causada pelo agente etiológico Rhinosporidium seeberi (R. seeberi) um microrganismo que infecta peixes, anfíbios e mamíferos como os seres humanos, sendo classificado como fungo pelo seu aspecto morfológico e histoquímico (LACAZ et al., 2002; FREDRICKS et al., 2000; TAVARES, 2007).

A doença se desenvolve com o aparecimento de lesões nas mucosas, mais frequentemente nas fossas nasais $(70 \%)$ e na conjuntiva ocular (10\%). Além das mucosas, a pele e as regiões da genitália externa também podem ser acometidas, com menor frequência. As lesões características são pólipos, geralmente sésseis ou vegetantes. A apresentação generalizada da patologia é rara, sendo mais comum sua manifestação localizada. O quadro clínico varia com o sítio infectado, sendo decorrente das consequências da formação polipoide (RIVITTI, 2014).

\section{METODOLOGIA}

O presente estudo trata-se de uma revisão, no qual as buscas dos artigos sobre o tema foram realizadas no US National Library of Medicine National Institutes of Health (PubMed), Literatura Latino-Americana e Caribe em Ciências da Saúde (Lilacs), Scientific Electronic Library Online (SciELO) e Google Acadêmico. A pesquisa foi desenvolvida por meio do cruzamento entre os seguintes descritores: "rhinosporidiosis", "nasal polyps", "mesomycetozoea" e "mycosis". Foram selecionados artigos escritos em inglês, português, espanhol e francês, com foco nas publicações das últimas duas décadas, isso é, de 2000 até 2020; porém, visto a quantidade limitada de trabalhos publicados sobre o assunto, os textos mais consagrados e citados acerca do tema ainda foram selecionados, mesmo que de anos anteriores. Além dos artigos selecionados, foram usados livros que contemplam o tema e que puderam contribuir com a construção desta revisão, artigos publicados anteriormente pelos autores do presente estudo, assim como artigos sugeridos que se associam ao tema pela base de 
dados durante a busca. Dessa forma, foram incluídos artigos originais, pesquisas quantitativas e qualitativas, estudos retrospectivos, artigos de revisão sobre o tema e estudos de casos.

\section{PARASITO}

A Rinosporidiose é decorrente da multiplicação do parasito Rhinosporidium seeberi em seu hospedeiro. O R. seeberi é mais prevalente ao sul do subcontinente indiano, mas pode ser encontrado também nas Américas, na Europa, na África e outros países asiáticos (FREDRICKS et al., 2000).

A taxonomia do agente sempre foi controversa. Nos anos de 1890, Malbran e, posteriormente, Seeber descreveram casos de pólipos nasais de pacientes vivendo na Argentina. Nesta descrição, foram relatados dois casos de pólipos que teriam sido causados por um esporozoário (LOH et al., 2001; LACAZ et al., 2002). Posteriormente, em 1923, Ashworth descreveu o ciclo de vida deste patógeno e chegou à conclusão que se tratava de um fungo, propôs o nome de Rhinosporidium seeberi (PRAKASH, JOHNNY, 2015). Desde então, o microrganismo tem sido considerado um fungo pela maioria dos autores. No entanto, sua taxonomia continuou sendo amplamente debatida (FREDRICKS et al., 2000).

Atualmente sabe-se que o R. seeberi não se trata de um fungo clássico, mas do primeiro patógeno humano do clado DRIPs, também conhecido como Mesomycetozoea, sendo clado um grupo de organismos originados de um ancestral evolutivo comum. Essa descoberta se deu somente no final do século XX, por meio da análise filogenética da subunidade menor do gene rRNA de parasitos aquáticos (RAGAN et al., 1996). Hoje, o R. seeberi tem sua taxonomia descrita como: pertencente ao super-reino Eukaryota, à classe Ichthyosporea, à ordem Dermocystida, ao gênero Rhinosporidium e à espécie seeberi (NCBI, 2017).

Quanto à sua morfologia, apresenta células esféricas e isoladas, com seis micrômetros de diâmetro, que se desenvolvem e se tornam esporângios com o diâmetro de até 300 micrômetros. Estes esporângios são a forma madura do organismo e contêm em seu interior numerosos endósporos em diferentes etapas de desenvolvimento que se organizam em posições características. É esta organização dos endósporos maduros, em amadurecimento e imaturos que permite o diagnóstico diferencial da Rinosporidiose e de outras lesões por organismos endosporuladores (LACAZ et al., 2002; MURRAY, ROSENTHAL, PFALLEN, 2016). Pela 
observação de seu núcleo, acredita-se que o patógeno apresente quatro cromossomos e um complexo ciclo de vida (DELFINO, COLETA, MENDOZA, 2016).

No que diz respeito a esse ciclo de vida do parasito, a inoculação do patógeno ocorre no contato das mucosas nasais ou conjuntivas, previamente traumatizadas, com a água contaminada. Uma vez no tecido do hospedeiro, o R. seeberi sofre sucessivas mitoses originando os esporângios maduros que liberam endósporos no interstício. Esta liberação pode se dar pela ruptura do corpo do esporângio ou por meio de seus poros. Neste último caso, ocorre o rearranjo dos endósporos no interior do esporângio, seguido pela abertura de um poro apical na parede celular do R. seeberi e a liberação ativa dos endósporos (PEZZIN-PALHETA, PALHETA-NETO, FEIER, 2003; TAVARES, 2007). Uma observação apontada por estudos sugere um fator estimulante da água nos esporângios de R. seeberi (MENDOZA et al, 1999). Sendo assim, considera-se que uma fase da vida deste patógeno possa ocorrer na água e areia contaminadas, mas ainda não há uma teoria comprovada de seu ciclo de vida completo (PRAKASH, JOHNNY, 2015).

A presença de uma "zona germinativa" em esporângios maduros do R. seeberi foi relatada por muitos autores. Esta zona está sempre localizada oposta ao poro de saída e contém pequenos endósporos imaturos, entre três e cinco micrometros de diâmetro, dispostos em um lado da parede celular do R. seeberi. Essa área foi primeiramente relatada como contendo esporângios maduros, onde se observou que os pequenos endósporos ovais pareciam estar ativamente formados nessa região. Vale ressaltar que o R. seeberi não se desenvolve em meios artificiais e suas descrições são inteiramente baseadas em seu comportamento no tecido infectado (DELFINO, COLETA, MENDOZA, 2016).

Histologicamente, corantes típicos de fungos como a Metenamina de Prata de Gomori (GMS) e o Ácido Periódico Schiff (PAS) (IMAGEM 1), bem como a Hematoxilina-Eosina (H\&E) (IMAGEM 2), podem ser usados para coloração dos endósporos e esporângios. Estes últimos apresentam-se como pontos brancos e são especialmente evidentes em sítios afetados (DAS, 2011). 


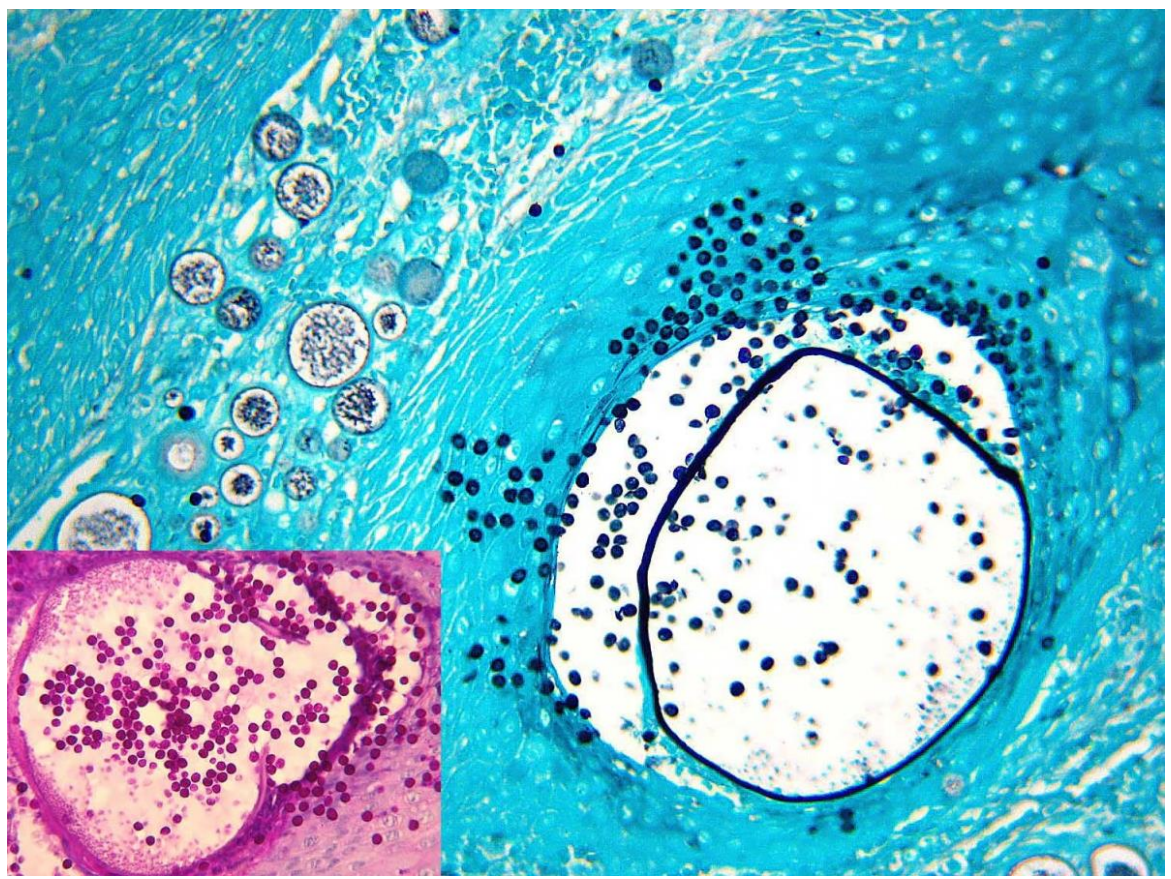

Imagem 1: Coloração de prata com metenamina de Gomori e, na inserção, coloração com ácido periódico de Schiff (imagem obtida de: MORELLI et al., 2006).

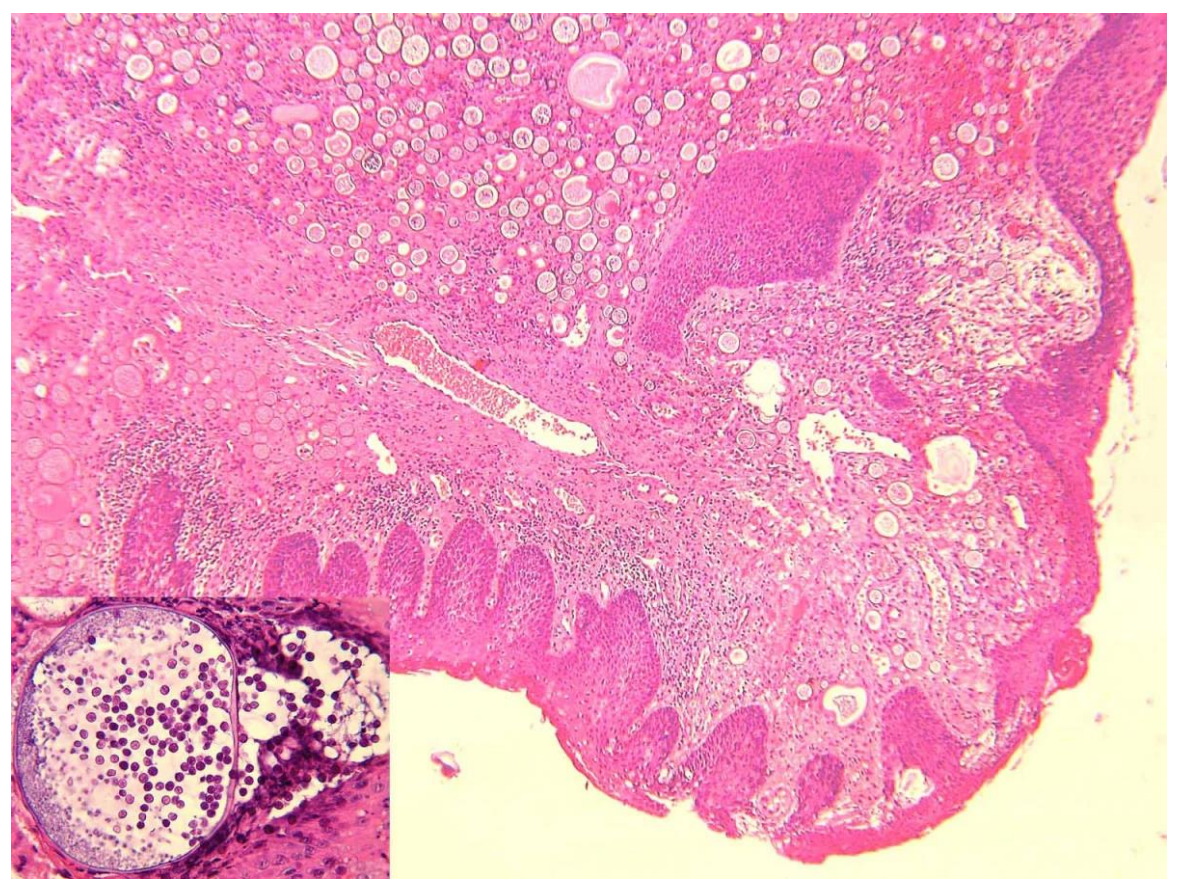

Imagem 2: Imagem histológica, corada com hematoxilina e eosina, do estroma fibroconectivo polipóide de uma mucosa nasal infectada pelo R. seeberi, recoberto por epitélio escamoso estratificado, contendo diversos cistos globulares. Cada um desses cistos representa um esporângio de parede espessa contendo numerosos esporos em diferentes estágios de desenvolvimento. $\mathrm{Na}$ inserção, cisto globular contendo endósporos (imagem obtida de: MORELLI et al., 2006). 


\section{EPIDEMIOLOGIA}

Como já dito, a Rinosporidiose é uma doença endêmica do subcontinente indiano. No entanto, por mais que essa seja sua origem, seus relatos estão presentes em mais de 70 países (PRAKASH; JOHNNY, 2015). No Brasil se é especialmente suscetível à doença graças ao seu clima tropical, favorável ao desenvolvimento do fungo. O país apresenta seu maior número de casos concentrados na região nordeste, principalmente no estado do Maranhão, que já se caracteriza como uma região endêmica da enfermidade (ALMEIDA et al., 2016).

As características hidrofílicas desse microrganismo podem ser sustentadas pela sua apresentação epidemiológica, onde sua incidência é significativamente maior em pessoas que entram em contato com água estagnada e trabalham com o solo, como os agricultores de arroz (LACAZ et al., 2002; PRASAD et al., 2015; ALMEIDA et al., 2016).

Há também diferença da prevalência do tipo de Rinosporidiose entre os sexos. A Rinosporidiose nasal, onde o pólipo se encontra no sítio nasal ou nasofaringe, afeta especialmente homens adultos, entre 20 e 40 anos. Por outro lado, a Oculosporidiose, quando se acomete a mucosa conjuntiva, tem maior prevalência no público feminino (MADANA et al., 2010).

\section{PATOGÊNESE}

O tecido do estroma fibromixomatoso da mucosa é invadido pelo agente que se multiplica, levando à hiperplasia e à alta vascularização tecidual, com uma resposta inflamatória de carácter granulomatoso crônico. A presença das células gigantes, encontradas ao redor dos esporângios, é acompanhada de linfócitos e macrófagos. Estes podem ser vistos no interior dos esporângios, ao redor dos endósporos, porém dificilmente conseguem erradicar o patógeno, que já está em grande número (MENDOZA, VILELA, 2009; CAPOOR et al., 2009). Quanto a reincidência da doença, é provável que ocorra com a disseminação dos endósporos para o tecido adjacente (MOHAPATRA, BANUSHREE, 2014). 


\section{CLÍNICA}

A Rinosporidiose apresenta evolução lenta, assim, seus sintomas podem aparecer apenas meses ou anos após o primeiro contato do indivíduo com o patógeno. A doença se manifesta através de uma lesão; polipoide ou vegetante, dependendo da forma em que o revestimento for danificado; sendo altamente vascularizada e friável, devido sua inflamação granulomatosa típica (IMAGEM 3). Como já visto, tais lesões acometem tipicamente o sítio nasal e a nasofaringe, mas lesões de envolvimento ocular também são comuns (TAVARES, 2007; DAS et al., 2011; CAPOOR et al., 2009). Com menos frequência, observa-se, também, lesões em: lábios, úvula, no palato, no maxilar, na epiglote, no esôfago, na laringe, na traqueia, nos brônquios, nos ouvidos, no couro cabeludo, na vulva, na vagina, no pênis, no reto e pele (MOHAPATRA, BANUSHREE, 2014; RIVITTI, 2014). São raros os casos de lesões ósseas ou disseminações hematogênicas sistêmicas (MADANA et al., 2010).

obtida de: MORELLI et al., 2006).

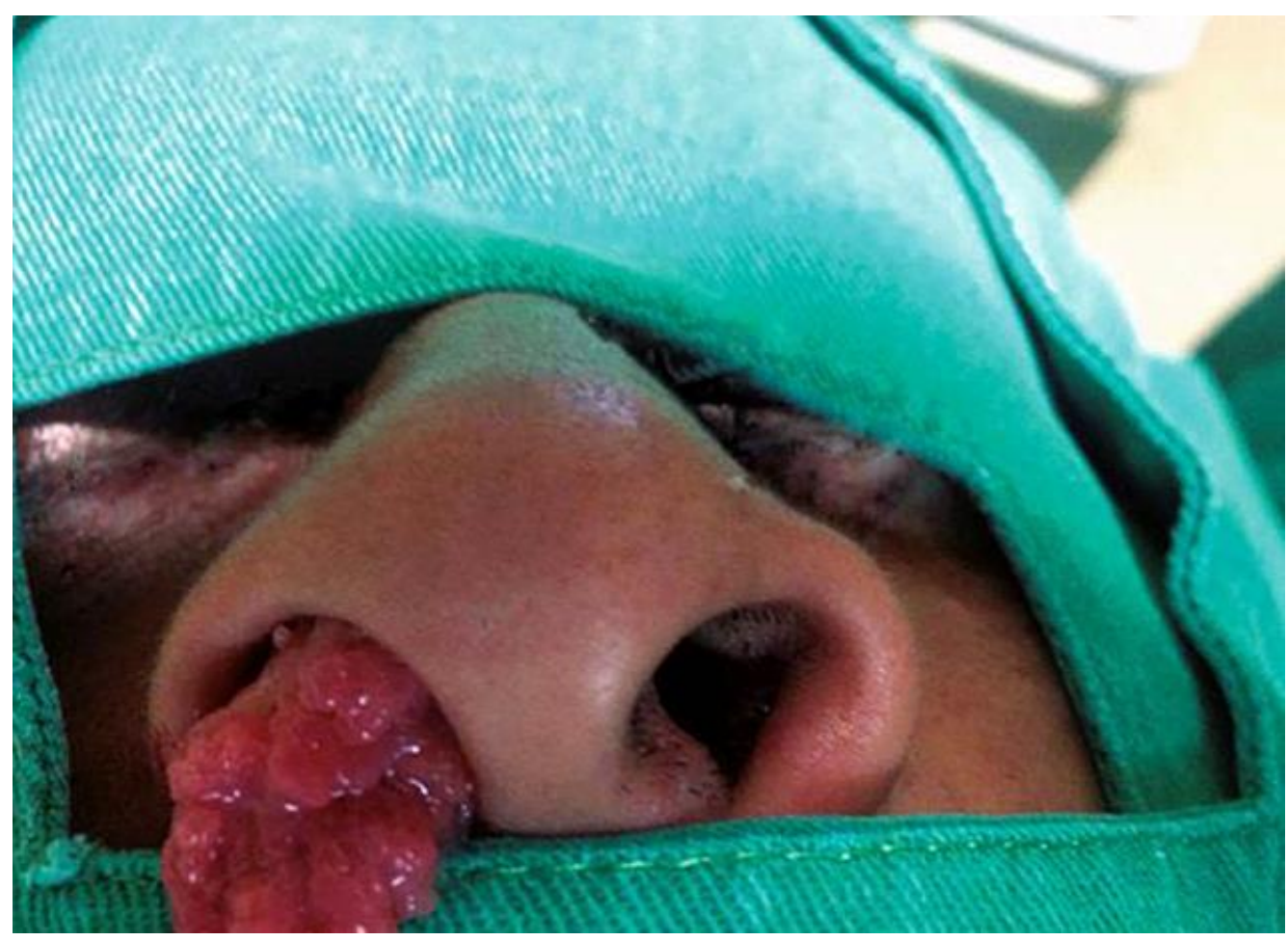

Imagem 1: Lesão polipoide, pendular e vascularizada originada na mucosa nasal de um paciente com rinosporidiose (imagem obtida de: ALMEIDA et al, 2016). 
O ser humano não é o único mamífero que serve de hospedeiro para o R. seeberi. No Brasil a maior quantidade de relatos é em equinos, mas há também relatos em bovinos e animais domésticos, como cães e gatos (LONDERO, SANTOS, FREITAS., 1977; LACAZ et al., 2002). No entanto, não há na literatura casos de transmissão entre animais e humanos.

A sintomatologia varia com o local acometido. No caso de uma Rinosporidiose nasal, há queixas de obstrução da narina, rinorreia e epistaxe (RIVITTI, 2014). Enquanto em casos de Oculosporidiose, há queixas de sensação de corpo estranho e epífora, quando o saco lacrimal é acometido é comum as lágrimas apresentarem sangue (BELLIVEAU et al., 2012; GICHUHI et al., 2014; TAVARES, 2007). Tratando-se especificamente dos casos de Oculosporidiose, os locais mais acometidos são a mucosa conjuntiva e o saco lacrimal representando entre $50 \%$ a $77,6 \%$ e $24 \%$ a $33 \%$ dos casos, respectivamente. Uma complicação do acometimento conjuntival é o estafiloma, pouco relatado pela baixa prevalência. Trata-se de uma precipitação anormal do trato uveal, que pode levar à ruptura e a perda de conteúdo intraocular, bem como a sua infecção, devido a dissolução dos tecidos esclerais, ocasionada pela sobreposição do R. seeberi. Além destes locais, a esclera e a pálpebra também são frequentemente acometidas. (SENARATNE et al., 2007; SENARATNE et al., 2011; BASU et al.,2016; NURUDDIN et al., 2014; SHAH et al., 2017; JOHN et al., 2017; MUKHERJEE et al., 2013).

As lesões cutâneas relacionadas a Rinosporidiose não são comuns e começam, geralmente, como papilomas friáveis que se tornam pedunculados. São especialmente propensas as disseminações, por isso devem ser tratadas com antecedência, a fim de evitar sua extensão. A Rinosporidiose cutânea pode manifestar-se como pápulas e nódulos verrucosos com manchas esbranquiçadas, crostas e sangramento na superfície. Pode ocorrer três tipos de lesões na pele: (1) lesões satélites, manifestação em que a pele adjacente à Rinosporidiose nasal é envolvida secundariamente; (2) lesão na pele generalizada com ou sem envolvimento nasal, ocorrendo por disseminação hematogênica do organismo; (3) lesão cutânea primária decorrente da inoculação direta de organismos na pele (KUMARI et al., 2009). É possível, também, a presença de infecções bacterianas secundárias recorrentes, com disseminação para sítios adjacentes (CAPOOR et al., 2009).

Quanto ao diagnóstico diferencial, deve se considerar o local acometido pelo patógeno. Na Oculosporidiose, é importante que se exclua a possibilidade de se tratar de um papiloma escamoso conjuntival (GICHUHI et al., 2014). Já no caso de lesões genitais deve ser diferenciado de tumores malignos e condilomas. As lesões retais e cutâneas devem ser 
diferenciadas de varizes hemorroidárias e verrugas vulgares, respectivamente (PEZZINPALHETA, PALHETA-NETO, FEIER, 2003).

Incluem diagnósticos diferenciais relevantes: pólipos nasossinusais, papiloma invertido, nasoangiofibromas, epiteliomas, leishmaniose, granuloma piogênico, coccidioidomicose, paracoccidioidomicose, criptococose, aspergilose e rinoscleroma (IGREJA, SIQUEIRABATISTA, MIRANDA, 2001; PÉREZ et al., 2012).

\section{EXAMES LABORATORIAIS}

O diagnóstico laboratorial definitivo para a Rinosporidiose é realizado através da análise histopatológica do tecido, visto que o cultivo do patógeno em laboratório não é possível. A análise pode ser realizada facilmente por citologia de aspiração seguida do exame microscópico com Hidróxido de Potássio a 10\% ou coloração de Papanicolau. A impressão Giemsa também pode ser usada (SEN et al, 2020). Deve-se observar a presença de um epitélio hiperplásico vascularizado, com cistos globulares que devem apresentar diferentes tamanhos visto que englobam esporângios em diferentes estágios de maturação (HERR et al, 1999; KUMARI et al., 2009).

No caso de Rinosporidiose nasal, exames de imagem, como Endoscopia Nasal, Tomografia Computadorizada e Ressonância Nuclear Magnética das Cavidades Paranasais, podem orientar o diagnóstico e a conduta terapêutica. No caso da Endoscopia Nasal, é possível observar a característica granular da lesão polipoide, a qual é friável e avermelhada devido a sua vascularização intensa. Os esporos no epitélio podem ser observados como pontos brancos sobre a mucosa (LOH et al., 2001; CAPOOR et al., 2009; DAS et al., 2011).

\section{TERAPÊUTICA}

O tratamento de escolha é remoção cirúrgica com eletrocoagulação da base das lesões. Apesar de apresentar menos riscos, casos de recorrência ainda são comuns em pacientes submetidos a esse tratamento. Vários medicamentos como a Dapsona, o Cetoconazol, a 
Ciprofloxacina e a Anfotericina B foram experimentados, mas a Dapsona ainda é a mais eficaz. Uma vez que pode haver risco de hemorragia e perfuração do septo nasal, a cirurgia é frequentemnte acompanhada da Dapsona como terapia secundária (VENKATESWARAN et al., 1997; ARSECULERATNE, 2002; DAS et al., 2011; SEN et al, 2020). Tal medicamento acomete o funcionamento do esporângio, impedindo a sua maturação e acelerando a sua degeneração, além de aumentar a fibrose e interferir no metabolismo do ácido fólico do patógeno, prevenindo a reincidência e a ressecção cirúrgica inadequada (CAPOOR et al., 2009; MADKE et al., 2011; DAS et al., 2011; ALMEIDA et al., 2016).

O antibiótico Cicloserina, um agente antituberculoso, também é recomendado na Rinosporidiose. Estudos in vitro demonstraram que a concentração inibitória de 50\% (CI 50) da Cicloserina contra o parasito é de $10 \mu \mathrm{g} / \mathrm{ml}$. CI $50 \mathrm{de}<100 \mu \mathrm{g} / \mathrm{ml}$ é considerado como uma terapêutica eficaz e dos oito agentes antimicrobianos testados em humanos, a cicloserina teve os menores valores de CI 50 (JOHN et al, 2017). O mecanismo de ação dos antibióticos ainda não está claro, primeiro pela incerteza quanto a caracterização do R. Seeberi, que ja recebeu diversas classificações ao longo dos anos; segundo por se tratar de um organismo naturalmente aquático e muito difícil de se isolar em cultura (JANARDHANAN et al, 2016).

O tratamento primariamente medicamentoso apresenta eficácia limitada, provavelmente pela quantidade de elementos fúngicos ser muito superior que a de componentes vasculares e ser estruturalmente muito maior que as células do sistema imune (MADKE et al, 2011). Além disso, a impenetrabilidade da parede esporangial também tem sido indicada na falha do tratamento medicamentoso e na de uma resposta imune de sucesso (WOODARD, HUDSON, 1984; ALMEIDA et al, 2016).

\section{PROFILAXIA}

O solo, com partículas de fezes secas de animais, e a água podem estar contaminados por esporos do fungo (MEARS, AMERASINGHE, 1992); assim, a inalação da poeira e/ou contato das mucosas com água contaminada seriam meios de transmissão. De acordo com Arseculeratne, Sumathipala e Eriyagama (2010) a fonte mais comum de infecção (84\%) é a água de lagos, seguida da água de rios (11\%) e da água de poços domésticos (5\%). A profilaxia 
básica consiste em evitar o contato com águas contaminadas, principalmente em regiões endêmicas de grande relevância para a prevenção na região amazônica, tendo em vista a participação dos rios no estilo de vida dos locais (PEZZIN-PALHETA, PALHETA-NETO, MOURA, 2007; PEZZIN-PALHETA, PALHETA-NETO, FEIER, 2003).

\section{CONSIDERAÇÕES FINAIS}

Ao avaliar as informações articuladas e os padrões epidemiológicos expressos pela Organização Mundial de Saúde (OMS) conclui-se que a Rinosporidiose é uma doença de raros relatos, apesar de sua ampla distribuição geográfica, destacando-se o favorecimento para o desenvolvimento da doença em território nacional, em virtude do clima. Assim, esse fato explicita a dificuldade profissional em diagnosticá-la, logo, dificultando o acesso a tratamentos eficazes, que evitem recidivas clínicas. O pouco acesso ao conhecimento acerca da patologia representa o maior entrave relacionado ao diagnóstico correto, visto que a enfermidade pode ser confundida com outras patologias supracitadas. Apesar dessas adversidades, o diagnóstico clínico não é complexo, sendo realizado através de um exame histopatológico. Ademais, é importante ressaltar que o tratamento da Rinosporidiose é de fácil acesso, podendo sanar a doença sem maiores mazelas clínicas e efeitos adversos aos pacientes, embora haja o risco de reincidência.

\section{REFERÊNCIAS}

ALMEIDA FA et al. Rhinosporidiose: the largest case series in Brazil. Sociedade Brasileira de Medicina Tropical. 2016; 49(4):473-476.

ARSECULERATNE SN, SUMATHIPALA S, ERIYAGAMA NB. Patterns of rhinosporidiosis in Sri Lanka: Comparison with international data. Southeast Asian journal of tropical medicine and public health. 2010; 41(1):175.

ARSECULERATNE SN. Recent advances in rhinosporidiosis and Rhinosporidium seeberi. Indian Journal of Medical Microbiology. 2002; 20:119-131.

BASU SK et al. Rhinosporidiosis of lacrimal sac: An interesting case of orbital swelling. Journal of Natural Science, Biology and Medicine. 2016; 7(1):98-101.

BELLIVEAU MJ et al. Bloody tears from lacrimal sac rhinosporidiosis. Canadian Journal 
of Ophthalmology. 2012; 47(5):23-24.

CAPOOR MR et al. Rhinosporidiosis in Delhi, North India: case series from a non-endemic area and minirreview. Mycopathologia. 2009; 168:89-94.

DAS S et al. Nasal rhinosporidiosis in humans: new interpretations and a review of the literature of this enigmatic disease. Medical Mycology. 2011; 49:311-5.

DELFINO DS, COLETA R, MENDOZA L. Rhinosporidium seeberi Nuclear Cycle Activities Using Confocal Microscopy. Journal of Parasitology. 2016, 102(1):60-68.

FREDRICKS DN et al. Rhinosporidium seeberi: a human pathogen from a novel group of aquatic protistan parasites. Emerging Infectious Diseases journal. 2000; 6:273-8.

GICHUHI et al. Ocular rhinosporidiosis mimicking conjunctival squamous papilloma in Kenya - a case report. BMC Ophthalmology. 2014; 14:45.

HERR et al. Phylogenetic analysis of Rhinosporidium seeberi's 18S small-subunit ribosomal DNA groups this pathogen among members of the protistan mesomycetozoa clade. Journal of Clinical Microbiology. 1999; 37(9):2750-2754.

IGREJA RP, SIQUEIRA-BATISTA R, MIRANDA LP. Rinosporidiose. Medicina tropical: abordagem atual das doenças infecciosas e parasitárias. Rio de Janeiro: Cultura Médica; 2001. JANARDHANAN et al. Elusive treatment for human rhinosporidiosis. International Journal of Infectus Diseases. 2016, 48:3-4.

JOHN D et al. Disseminated Rhinosporidiosis with Conjunctival Involvement in an Immunocompromised Patient. Middle East African Journal of Ophthalmology. 2017;24(1):51-53.

KUMARI R et al. Disseminated cutaneous rhinosporidiosis: varied morphological appearances on the skin. The Indian Journal of Dermatology, Venereology and Leprology. 2009; 75:68-71.

LACAZ CS et al. Rinosporidiose. Tratado de micologia médica Lacaz. São Paulo: Sarvier. 2002.

LOH KS et al. Rhinosporidiosis: differential diagnosis of a large nasal mass. Otolaryngology Head and Neck Surgery. 2001; 124(1):121-122.

LONDERO AT, SANTOS MN, FREITAS JB. Animal rhinosporidiosis in Brazil. Mycopathologia. 1977; 60(3): 171-173.

MADANA J et al. Rhinosporidiosis of the upper airways and trachea. The Journal of Laryngology \& Otology. 2010;124(10): 1139-1141.

MADKE B et al. Disseminated cutaneous with nasopharyngeal rhinosporidiosis: light microscopy changes following dapsone therapy. Australasian Journal of Dermatology. 2011; 52:4-6. 
MEARS T, AMERASINGHE C. View from beneath: Patholgy in focus, Rhynosporidiosis. The Journal of Laryngology and Otology. 1992:106:468

MENDOZA L et al. In vitro studies on the mechanisms of endospore release by Rhinosporidium seeberi. Mycopathologia. 1999; 148(1):9-15.

MENDOZA L, VILELA R. Anomalous fungal and fungal-like infections: lacaziosis, pythiosis, and rhinosporidiosis. Sao Paulo: Elsevier. 2009. p. 403-415.

MOHAPATRA M, BANUSHREE CS. Two rare cases of rhinosporidiosis of parotid duct: Case reports and review of literature. Annals of Maxillofacial Surgery. 2014; 4(2):234-236.

MORELLI L et al. Human nasal rhinosporidiosis: an Italian case report. Diagnostic Pathology. 2006. Disponível em: https://link.springer.com/article/10.1186/1746-1596-125\#citeas. Acessado em: 20 de abril de 2021.

MUKHERJEE B et al. Infestation of the lacrimal sac by Rhinosporidium seeberi: a clinicopathological case report. Indian Journal of Ophthalmology. 2013; 61(10):588-590.

MURRAY PR, ROSENTHAL KS, PFALLER MA. Rhinosporidiosis. Medical Microbiology. Philadelphia: Elsevier. 2016; p. 676-677.

National Center for Biotechnology Information (NCBI). Taxonomy. Disponível em: https://www.ncbi.nlm.nih.gov/taxonomy. Acessado em: 01 de setembro de 2020.

NURUDDIN M et al. Lacrimal sac rhinosporidiosis: clinical profile and surgical management by modified dacryocystorhinostomy. the International Journal on Orbital Disorders, Oculoplastic and Lacrimal Surgery. 2014; 33(1):29-32.

PÉREZ RIM et al. Diagnóstico diferencial de la rinosporidiosis: a propósito de um caso. Iatreia. 2012; 25(3):272-276.

PEZZIN-PALHETA AC, PALHETA-NETO FX, FEIER CAK. Rinosporidiose. Manual de infectologia. Rio de Janeiro: Revinter. 2003; 394-395.

PEZZIN-PALHETA AC, PALHETA-NETO FX, MOURA WJQ, RESQUE JE, LOBATO MF.. Rinosporidiose nasal: Uma doença incomum? Revista Brasileira de Otorrinolaringologia. 2007; 73(2).

PRAKASH M, JOHNNY JC. Rhinosporidiosis and the pond. Journal of Pharmacy and Bioallied Sciences. 2015; 7(1):59-62.

PRASAD V et al. Rhinosporidiosis: a chronic tropical disease in lateral pharyngeal wall. Journal of Clinical and Diagnostic Research. 2015; 9(5):1-2.

RAGAN MA et al. A novel clade of protistan parasites near the animal-fungal divergence. Proceedings of the National Academy of Sciences of the United States of America. 1996; 93:11907-11912.

RIVITTI EA. Rinosporidiose. Manual de dermatologia clínica de Sampaio e Rivitti. São 
Paulo: Artes Médicas. 2014; 387.

SEN S et al. Disseminated cutaneous rhinosporidiosis: Revisited. Indian Journal of Dermatology. 2020; 65(3): 204.

SENARATNE T et al. Ocular rhinosporidiosis with staphyloma formation: a case with unusual features. Eye and Brain. 2011; 12(3):1-4.

SENARATNE T et al. Ocular rhinosporidiosis with staphyloma formation: The first report in Sri Lanka. Journal of Infectious Diseases and Antimicrobial Agents. 2007; 24:133-141.

SHAH S et al. A case report of an unusual presentation of ocular rhinosporidiosis as a conjunctival cystic mass. The International Journal on Orbital Disorders, Oculoplastic and Lacrimal Surgery. 2017; 36(1):55-57.

TAVARES W. Rinosporidiose. Rotinas de diagnóstico e tratamento das doenças infecciosas e parasitárias. São Paulo: Atheneu. 2007; 906.

VENKATESWARAN S et al. Light and electron microscopic findings in rhinosporidiosis after Dapsone therapy. Tropical Medicine and International Health. 1997; 2:1128-1132. WOODARD B, HUDSON J. Rhinosporidiosis: ultrasuctural study of an infection in South Carolina. Southern Medical Journal. 1984; 77:1587-1588.

\section{Declaração de Interesse}

Os autores declaram não haver nenhum conflito de interesse

\section{Financiamento}

Financiamento próprio

\author{
Colaboração entre autores \\ Francisco Xavier Palheta Neto e \\ Rodrigo Siqueira-Batista foram \\ responsáveis pela proposição do tema, \\ obtenção das referências \\ bibliográficas e revisão de todo o \\ texto. Os demais autores, Bruno \\ Sérgio Cruz da Silva, Carolina \\ Ferreira Alves, Marina Brito dos \\ Santos e Victorya do Nascimento \\ Cavalcante, cuidaram da parte \\ dissertativa do artigo.
}

